\title{
Paisaje cultural y una nueva forma de entender el Patrimonio en Ecuador
}

\author{
Cultural landscape and a new way \\ of understanding Ecuador's heritage
}

José Marcelo León B. ${ }^{1}$

Resumen: El enfoque clásico de tratar el patrimonio cultural en Ecuador se traduce en el manejo verticalizado de los bienes patrimoniales. En este manejo las instituciones vinculadas organizan y planean la forma como se debe manejar, gestionar y utilizar estos recursos. El resultado final de este enfoque se traduce en acciones aisladas e individuales sobre el manejo de un determinado patrimonio, desvinculadas totalmente de los otros ámbitos patrimoniales, y del contexto territorial y geográfico donde se encuentran. Desde esta perspectiva clásica y verticalizada, cuando los planes de manejo y acciones de intervención en el patrimonio, aterrizan a contextos locales, emergen un conjunto de problemas, tales como la falta de apropiación y participación de la población local en las intervenciones, conflictos de intereses entre las instituciones y las poblaciones locales respecto a la valoración del patrimonio, y una falta de diálogo para la generación activa de normas y criterios para la elaboración de políticas de manejo y gestión local del patrimonio. Todas esta problemática pone de manifiesto el enorme reto para superar las formas clásicas de manejar los recursos naturales y patrimoniales: Se trata de poner en valor la integralidad patrimonial y territorial, incentivar la apropiación activa de la población, y desatar procesos organizativos metodológicos y pedagógicos que se conviertan en estrategias clave para la gestión óptima de los territorios, generando un desarrollo económico, social y cultural sostenible en beneficio de las comunidades que lo habitan y del fortalecimiento de sus patrimonios.

Palabras clave: Patrimonio cultural, territorio, valoración, políticas de manejo, gestión local.
Abstract: The classic approach to dealing with cultural heritage in Ecuador translates into the verticalized management of assets inherited from parents. This means that the institutions involved organize and plan the way these resources must be handled, managed and used. The final result of this approach leads to isolated and individual actions for managing a particular asset, completely unconnected from the other areas of cultural value and from the territorial and geographic context where they are found. From this classic and verticalized perspective, when the management plans and interventions with respect to the asset reach local contexts, a set of problems emerges, such as the lack of participation and commitment on the part of the local population in the interventions, conflicts of interest between the local institutions and populations with regard to the development of the assets, and a lack of dialog for the active generation of standards and criteria to draft handling policies and local management of the asset. This entire issue brings to light the enormous challenge of overcoming the classic ways of managing natural and heritage resources: This is about placing value on cultural and territorial completeness, stimulating the population's active participation, and setting methodological and pedagogical organizational processes in motion that become key strategies for the optimal management of the territories, generating a sustainable economic, social and cultural development to the benefit of the communities that inhabit them and the strengthening of their cultural assets.

Key words: Cultural heritage, territory, appreciation, management policies, local management.

\section{(Presentado: 5 de diciembre de 2017. Aceptado: 2 de febrero de 2018)}

\footnotetext{
1 Masterando en Paisaje, Patrimonio y Estudios Territoriales por el Instituto Internacional de Formación Ambiental (IIFA-España). Arquitecto Catalogador de Patrimonio Arquitectónico y Coordinador del Proyecto Paisajes Culturales en el Instituto Nacional de Patrimonio Cultural (Quito, Ecuador). E-mail: m_leon_bahotmail.com
} 


\section{INTRODUCCIÓN}

Las acciones sobre el patrimonio se han centrado exclusivamente en los centros históricos, en la monumentalidad o en ciertos bienes distintivos de una determinada localidad, cuyas acciones se limitan exclusivamente en proyectos de conservación o rehabilitación per se, sin estudios integrales y articulados de ese patrimonio respecto a otros recursos y a la realidad y problemática social, económica, productiva, cultural e incluso política de un determinado territorio.

Los problemas de apropiación y desvalorización de nuestro patrimonio, en gran manera son producto de esta antigua forma de manejar los bienes patrimoniales, situación que ha llevado al deterioro, degradación y en muchos casos desaparición de nuestro legado patrimonial.

El pensamiento equivocado del ciudadano respecto al patrimonio, es producto de una errada e ineficaz gestión y puesta en valor de los bienes y de una insuficiente difusión y socialización del verdadero valor de los recursos patrimoniales y su uso.

Se cree que al patrimonio hay que sacralizarlo, museizarlo, por tanto, no se lo puede tocar ni intervenir. Son parte de la historia, de nuestra identidad, pero el pueblo no vive, no come de la historia, del pasado. Son bienes para mirarlos y apreciarlos, pero no generan nada más.

Por otro lado, la falta o limitada apropiación estatal respecto a este tema, trae como consecuencia una carencia de políticas públicas, normativas, leyes y ordenanzas en beneficio del patrimonio, de los usuarios y portadores de esos recursos y de los territorios donde se encuentran.

El huaquerismo, los robos, el tráfico ilícito, las intervenciones ilegales, antitécnicas, los derrocamientos, la pérdida de la autenticidad y originalidad de los bienes patrimoniales son consecuencia de esta falta de conocimiento, valoración, apropiación y respeto del patrimonio cultural.

Las distinciones de varios sitios como Patrimonio Nacional del Ecuador y otros como Patrimonios Culturales y/o Naturales de la Humanidad, atrajeron por supuesto la inversión de grandes empresas, sobre todo en el campo turístico, detonando por un lado, desarrollo económico; pero por otro lado centralizando los recursos obtenidos, en estas entidades privadas, acrecentando una desigualdad entre los actores sociales, herederos legítimos de estos sitios, y los empresarios de servicios e infraestructura turística, obteniendo un escenario donde, por un lado se cuenta con una enorme riqueza en cuanto a la diversidad de recursos naturales y culturales, y de manera simultánea un escenario de profunda pobreza y desigualdad generada a partir de procesos de exclusión, marginación hacia las poblaciones y localidades portadores y creadores de las expresiones culturales auténticas y sabedores de los significados densos y profundos de las expresiones declaradas.

\section{¿Para qué hacemos Paisajes Culturales?}

La nueva visión de manejar y gestionar el patrimonio, trascendiendo del elemento a la importancia del contexto; desde la integralidad, dentro de un contexto territorial, de características geográficas, naturales, históricas, culturales propias, con la finalidad de dinamizar los territorios y generar un desarrollo económico, social y cultural sostenible en beneficio de las comunidades que lo habitan y de la conservación de sus patrimonios.

Esta mirada contextualizada permite abordar los diferentes ámbitos del patrimonio de una forma mucho más amplia y completa tomando en cuenta el entorno como producto de la relación naturaleza- ser humano. Desde esta mirada macro, se considera de vital importancia incurrir sobre esta nueva categoría, los paisajes culturales, proponiendo una nueva metodología de estudio que se enmarca dentro de los pronunciamientos y definiciones internacionales y sobre todo de las latinoamericanas, para crear una propia a partir de nuestra realidad nacional. Esta propuesta fundamentalmente se centra en la construcción de una Guía del Paisaje Cultural para la Gestión de los Territorios Culturales Ecuatorianos.

El propósito de este estudio, es fomentar y posicionar el uso de la categoría "Paisaje Cultural" en el Ecuador, como una nueva forma de entender, proteger, gestionar y difundir el patrimonio a través de la integralidad de los diferentes ámbitos que conforman el Patrimonio Cultural, dentro de un contexto territorial de singulares características, sean naturales, geográficas, productivas, socio culturales y patrimoniales, en beneficio de las poblaciones que lo ha- 
bitan; superando así la visión clásica e individual de manejar el Patrimonio Cultural en nuestro país.

Su objetivo es ser un instrumento que nos permita conocer el territorio; definir las claves de su formación y desarrollo; y determinar las pautas por las cuales podamos garantizar su sostenibilidad para el progreso de los pueblos. La Guía Metodológica para el Paisaje Cultural Ecuatoriano, constituye una caja de herramientas que aportará una metodología que permita paso a paso la identificación, caracterización, delimitación y valoración de los paisajes culturales, distribuidos en las ricas y diversas regiones biológicas y culturales del Ecuador.

Los paisajes culturales son procesos en constante movimiento y por ello deben leerse en sus características multiescalares y multidimensionales. En lo multiescalar nos referimos a su delimitación espacial, desde expresiones domésticas, extendiéndose por lo barrios, calles, caseríos, comunidades, ciudades y regiones. Lo multidimensional son aquellas expresiones que se han desencadenado a partir de las continuidades y rupturas a lo largo del tiempo, expresiones que se van manteniendo en las prácticas e imaginarios sociales y que de pronto por una situación determinada, se modifican, se desplazan y/o se dejan de practicar en un espacio específico.

\section{Metodología para trabajar paisajes culturales}

Pretendemos delimitar cuatro momentos fundamentales, si bien no los únicos, a través de los cuales sucede la constitución de un paisaje cultural: identificación, caracterización, delimitación y valoración, un elemento transversal es la gestión que ocurre a cada paso y que se expresa en dos dimensiones simultáneas (Figura 1).

\section{IDENTIFICACIÓN}
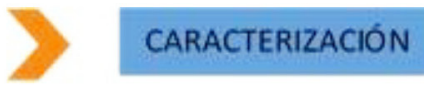

\section{DELIMITACIÓN}

\section{VALORACIÓN}

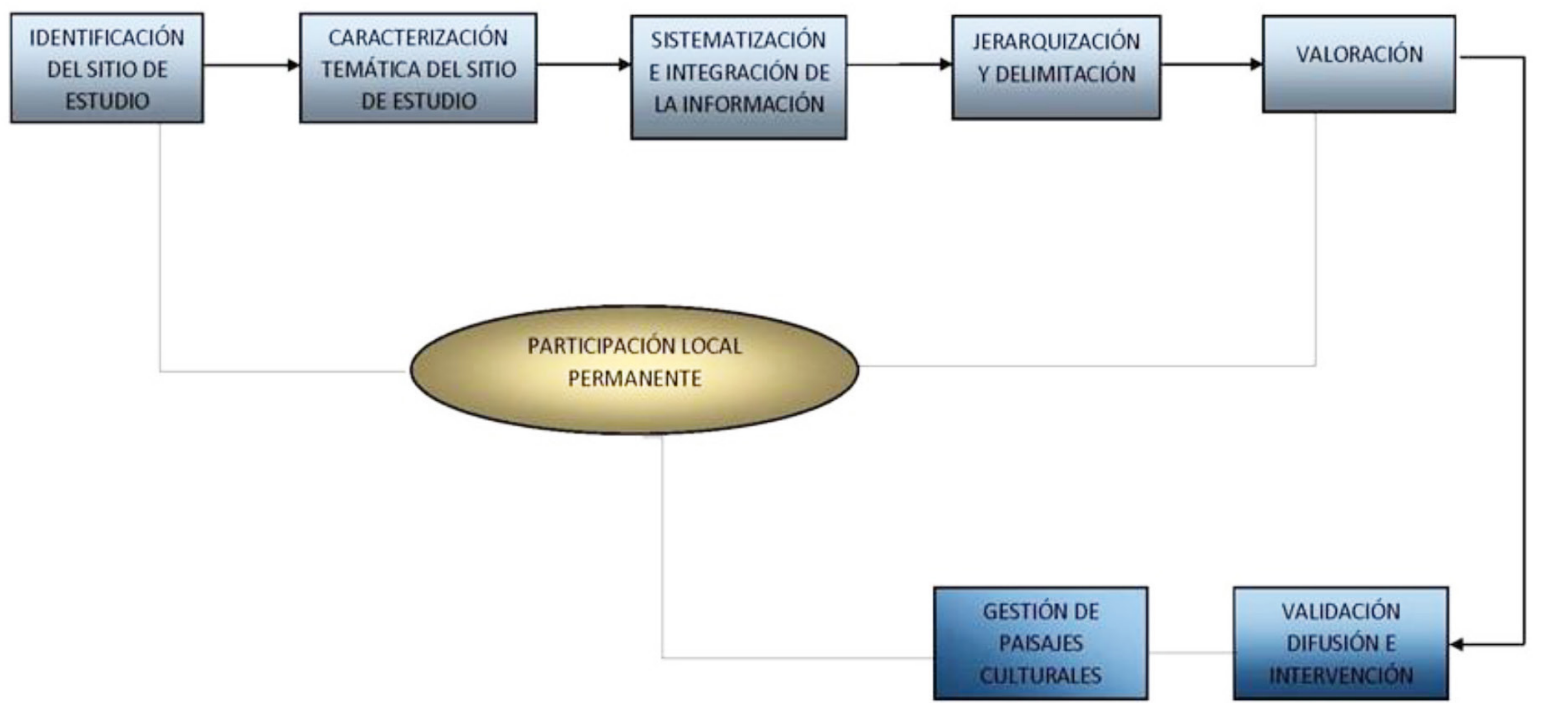

Figura 1. Propuesta metodológica. 
La primera es la dimensión del estado vinculada con normas, leyes, instituciones y formas operativas de políticas públicas, sus funcionarios y ejecutores. La otra dimensión es la gestión social, que se mueve con la gente cara a cara. Decimos que la gestión es transversal y multidimensional, porque los interesados en identificar, caracterizar, delimitar y valorizar un paisaje cultural deberán todo el tiempo tener en cuenta las voces tanto de instituciones gubernamentales y sistemas normativos, y sobre todo, la palabra y el saber de los habitantes del lugar. Es por esta característica que los paisajes culturales se convierten en unidad de gestión social, política y económica; mediante su comprensión y manejo se pueden construir intervenciones incluyentes, eficientes e interculturales, coadyuvando así en la generación de procesos pedagógicos y organizativos de cara al desarrollo local y a la autonomía de los grupos que se encuentran involucrados.

El proceso de identificación nos ubica en un espacio y tiempo con respecto a un territorio determinado; por su parte, la caracterización nos detalla y describe lo que contiene el espacio; la delimitación, nos ayuda a construir fronteras y unidades para organizar las expresiones al interior y exterior de los territorios; y, finalmente, el proceso de valoración nos ayuda a jerarquizar en un proceso de colaboración, los paisajes culturales. Cabe señalar, que durante todo el proceso la participación de las poblaciones involucradas es activa y permanente, facilitando de esta manera el proceso de validación de la investigación, y las posteriores acciones de difusión y gestión de los paisajes culturales.

\section{La identificación de un paisaje cultural}

La identificación de un sitio para el estudio de paisajes culturales, puede surgir de maneras diversas o simultáneas, a través de información existente formal o informal sobre un territorio determinado; por pedido expreso formal o informal de un conglomerado social, de una localidad (actores locales), o de entidades competentes, autoridades locales sean Gobiernos Autónomos Descentralizados, Juntas Parroquiales, Prefecturas, Gobernaciones, etc; actores institucionales, quienes tomando en cuenta ciertas particularidades, relevantes singulares desde los ámbitos geográficos, naturales, históricos, socio culturales de un espacio territorial, y que son identificadas y reconocidas local, regionalmente o incluso de manera nacional, ven la necesidad de gestionar de alguna manera dichos territorios (Figura 2). Debemos mencionar que todo este acercamiento sea con actores locales, institucionales y sociedad en general, ocurre a través de lo que se conoce como un diálogo de saberes, a través de la cual se irá comprendiendo y conociendo de manera preliminar la importancia del sitio y definir la factibilidad y viabilidad del proyecto. El diálogo de saberes es una actividad primordial para empezar a entender el territorio desde diferentes miradas, por lo que su labor debe ser permanente durante todo el proceso.

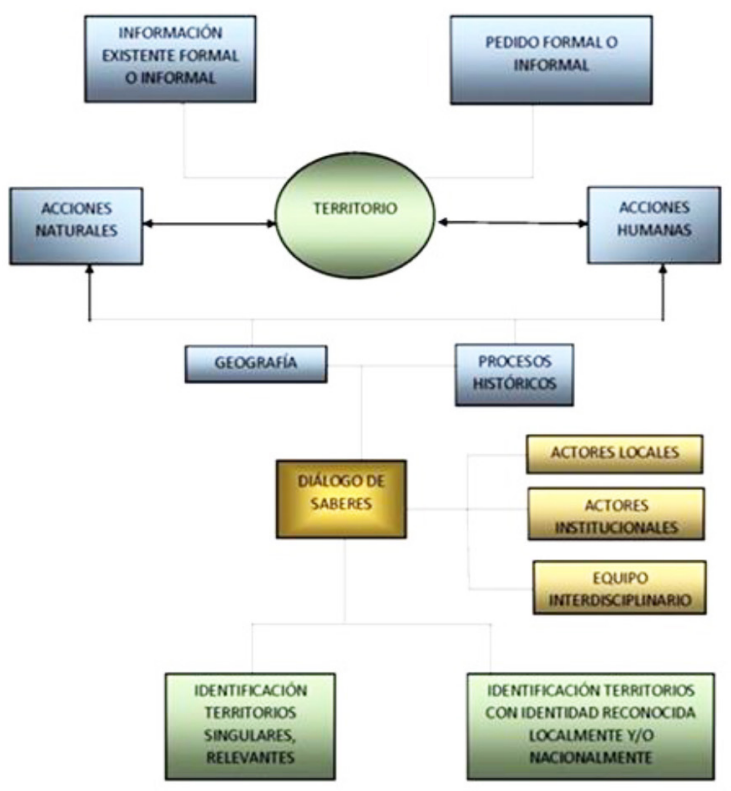

Figura 2. Identificación.

La identificación se convierte en un proceso de adjetivación, caracterización y formulación de aquellos elementos constitutivos y definitorios para un paisaje cultural, y establece los indicadores que guiarán a los investigadores para su definición y a la población local para su reconocimiento. Algunos de los factores que permiten la selección de un territorio de estudio son: disponibilidad, accesibilidad al paisaje cultural y sus elementos, interés y la participación de los habitantes del lugar y la voluntad política de trabajar el proceso investigativo.

\section{La caracterización de un paisaje cultural}

Una de las necesidades primarias para la realización de la caracterización del paisaje cultural tiene que ver con la elaboración de un estado de la cuestión o estado del arte del territorio que se pretende explorar (Figura 3). Para ello consideramos de vital importancia volver la mirada a varios recursos de información para poder iniciar la caracterización de un paisaje cultural: 
- Investigaciones previas: Los trabajos de investigación, realizados desde distintos sectores de la sociedad, como la academia mediante universidades, centros de investigación, las tesis, memorias de proyectos, ofrecen desde distintas disciplinas conocimientos actualizados y especializados sobre un determinado lugar y en un período histórico específico. De la misma forma los artículos de investigación, revistas, libros, describen y analizan un entorno. Las publicaciones en medios digitales como revistas científicas y otras de arbitraje académico, nos ofrecen un acceso adecuado y conveniente a la información, y constituyen una primera fuente de información pertinente y calificada para iniciar las características de un paisaje cultural. Los inventarios del patrimonio cultural y natural, serán de vital importancia y nos darán luces para poder entender y comprender cualitativa y cuantitativamente sobre la riqueza y estado de los recursos naturales y patrimoniales con los que cuenta un determinado territorio.

- Censos: Los censos son indispensables para la caracterización de la población de un determinado territorio y las variables como: género, generación, hablantes de lengua indígena, ocupación y estructura familiar y doméstica, son caminos recurrentes por los cuales se caracteriza el elemento social del paisaje. Los censos se pueden ocupar de manera procesual, en otras palabras, podemos comparar cifras de años distintos para establecer tendencias poblacionales y su impacto sobre el paisaje. Las bases censales contienen un conjunto de variables amplias y detalladas que mediante la articulación de sus indicadores dan a conocer datos generales de universos de investigación vastos, inscritos en temáticas específicas, como censos agrícolas, económicos, de población y vivienda, entre otros.

- Archivos históricos: Un paisaje cultural es una construcción histórica que va transformándose a lo largo del tiempo, es por ello que tenemos que conocer cuáles han sido sus distintas rupturas y continuidades de fenómenos culturales y naturales inscritos en la piel del territorio. Hay distintos temas que en la caracterización histórica podemos utilizar, como aquellos documentos legales de linderos con croquis y mapas, las partidas arquitectónicas con planos de edificios o espacios públicos, fundos legales, relaciones laborales de la época de las haciendas y archivos religiosos con censos y actividades de dicho sector y civiles varias.
- Trabajos etnográficos: Con temas que tienen que ver con cultura material, organización social, territorio, identidad, relaciones con la naturaleza, cosmovisión, ritualidad y sistemas económicos, se puede construir un conjunto de conocimientos detallados para la descripción pormenorizada de las tradiciones vivas de las comunidades que constituyen una región.

El trabajo de campo constituye una actividad transversal. El estar en el territorio a estudiar implica la comprensión articulada de conocimientos previos o abstractos del contexto, con experiencias nuevas relacionadas con el acercamiento in situ a la realidad. Además, establece el punto de partida para continuar la caracterización del paisaje cultural. La interdisciplinariedad de esta actividad ayudará a constituir una lectura densa de descripciones del paisaje, información que deberá ser registrada de manera articulada y que coadyuvará de manera directa en la construcción de los resultados y las delimitaciones paisajísticas, ya que una mirada densificada desde distintas perspectivas, sirve para integrar o fragmentar las variables necesarias para resaltar los rasgos de autenticidad o excepcionalidad de un elemento del paisaje. El trabajo de campo estará enfocado a caracterizar el territorio desde los siguientes ámbitos:

- Caracterización biofísica: Constituida por aquellos componentes que establecen la estructura y la función ecológica de un territorio determinado. Agua, suelo, capa vegetal, fauna. Si bien cada elemento se interrelaciona entre sí, es importante no dejar de mirarlos en cuanto a los manejos y gestiones que el humano en ellas realiza, delineando y utilizando lo que la naturaleza a lo largo de procesos milenarios ha construido.

- Caracterización socio histórica: la presencia humana ha delineando, a lo largo de distintas etapas históricas, manejos específicos sobre su naturaleza, expresados en distintos aspectos de su sociedad y cultura. Las rupturas y continuidades poblacionales nos hablan de la dinámica del hombre en su entorno, mostrándonos con ello los elementos que no deben de escapar a nuestra mirada. Se sugiere las siguientes etapas como un marco de referencia general: Antecedentes prehispánicos, coloniales, la independencia, república, siglo XX y el tercer milenio.

- Tradiciones vivas: Entendemos por tradiciones vivas a toda aquella manifestación donde la cultura ha intervenido la naturaleza, plasmando dicha interacción en un 
conjunto de saberes, creencias y prácticas que quedan en manifiesto a lo largo de la vida sagrada y cotidiana de comunidades y sociedades, contenidos en los mismos ámbitos que describe la UNESCO en su definición de patrimonio inmaterial. En esta caracterización se describe y analiza las siguientes manifestaciones: la lengua, actividades económicas, cosmovisión y territorios, artes culinarias y medicinales, tecnologías populares.

- Espacio edificado: (arquitectónico), representa modos de vida que transitan a lo largo de distintas generaciones dejando en piedra testigos de las formas culturales, con las cuales se edifica una sociedad. Mediante materiales y técnicas, el espacio edificado constituye la experiencia del imago arquitectónico que traduce, interpreta y reinventa aquellos usos y manejos provenientes de tradición constructiva local determinada con el paisaje, hasta una de ruptura que corta y transgrede el paisaje local. Las arquitecturas vernáculas, los espacios públicos y monumentos, junto con los puentes y caminos, son las expresiones que resaltamos para el registro de este apartado. El siguiente diagrama nos ayuda a entender de mejor manera todo lo mencionado.

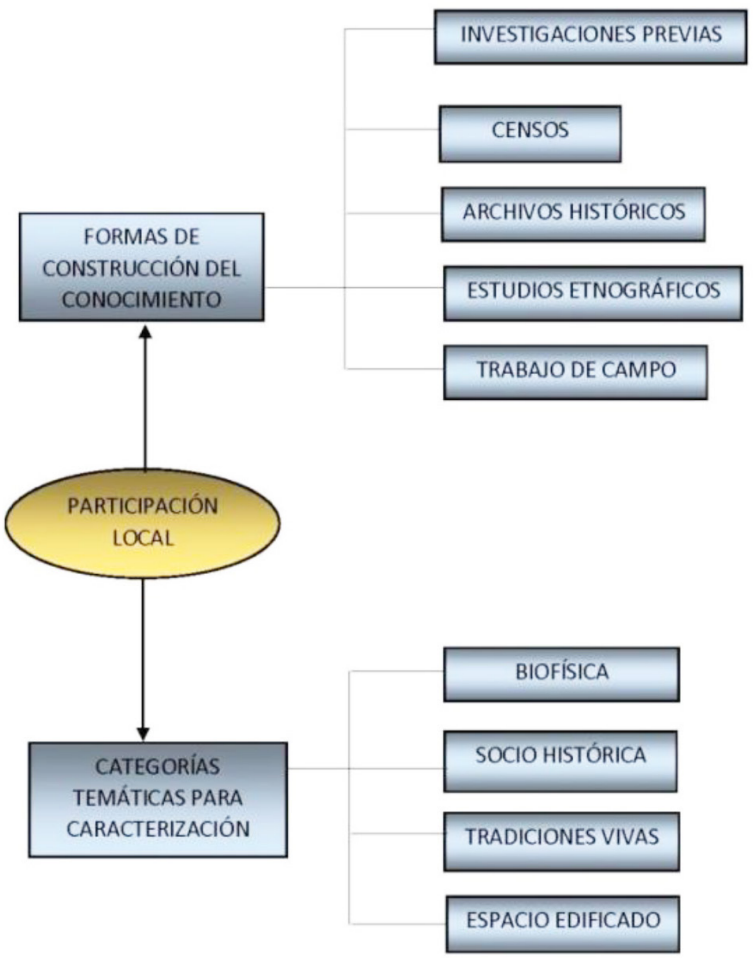

Figura 3. Caracterización, sistematización e integración de la información.
Etapa clave del proceso ya que toda la información generada se la debe organizar, ordenar, analizar, sistematizar y estructurar. Tomando en cuenta que este es un trabajo multidisciplinario e interdisciplinario, el éxito del proceso está en saber interpretar los resultados desde las diferentes disciplinas del saber y enlazar de manera coherente y vinculante la información para lograr concebir conocimientos completos, calificados, articulados, holísticos expresados en productos concretos.

Se trata de trabajar de manera integrada los distintos temas organizando la información a partir de tareas específicas. Ejercicios integradores que pronuncian la relación naturaleza y cultura; ejercicios de sistematización de información (previa y de campo) en los que se identifique elementos de características auténticas, relevantes y/o excepcionales. Elaboración de informes limitados en los que se ordene y sistematice cada uno de los ámbitos investigados, construcción paralela de base de datos de imágenes relativas a cada temática, construcción de mapas temáticos, mismos que aparecen como una representación concreta del espacio delimitado con símbolos diferenciales, intenciones diversas y accidentes geográficos particulares, los cuales se integran de manera articulada en ámbitos como el uso de la naturaleza, la historia, la economía, la religión, entre otros temas.

Usos de mapas construidos en diferentes épocas y etapas de transformación del territorio, cotejados con los mapas que se generen, nos ayudarán a obtener delimitaciones previas, comprender los territorios del presente y observar las rupturas y continuidades los cuales nos brindarán un criterio histórico que permite darle al mapa dinamismo. La elaboración de los mapas se construye de manera colectiva, desde miradas multidisciplinarias, los cuales nos ayudarán a ampliar los horizontes donde usualmente se observan barreras.

Usualmente, los mapas se inician con un corte (shape) o sea, una delimitación del territorio a partir de un criterio. Aquel que usualmente se utiliza para iniciar este camino es el criterio biofísico, articulando en términos cartográficos, climas, tipos de vegetación, fauna, tipos de suelos, hidrografía, elevaciones y usos de suelo.

Posterior a esta información, se integran los criterios que tienen que ver con los perfiles demográficos de la población, sus actividades económicas, sus centros poblacionales, así como también sus características culturales ligadas a los grupos étnicos y etnolingüísticos. 
Es por ello, que el mapa del paisaje será cambiante a lo largo del proceso de conformación, ya que se expande y contrae según la información con la que se va alimentando. Asimismo, se transforma según los rasgos a los cuales se les quiera otorgar énfasis.

La labor de integrar implica el ordenamiento temático de la información a partir de rubros limitados, y también tiene que ver con la articulación activa de estos temas para mostrar la idea de integralidad del paisaje. Cuando la información se está integrando progresivamente se va delimitando la expresión del paisaje cultural. La profundidad y la extensión con la cual se cuenta es la materia prima por la cual se realiza una delimitación ex situ, la cual corresponde a la mirada de los expertos reunidos en el equipo de trabajo, que mediante sus conocimientos articulados podrán definir la expresión o expresiones más sobresalientes.

\section{Delimitación, jerarquización y valoración del paisaje cultural}

Cuando se tiene una idea clara articulada de lo que contiene un territorio, se trata de establecer sus distintos elementos que la constituyen los cuales nos ayudaran a definir las posibles formas de jerarquizar y valorar el territorio. De ahí que una de las actividades primarias que se desencadenan de manera simultánea a la delimitación, es la estructuración hacia dentro y hacia fuera de polígonos de acción. Llamamos polígonos de acción a los perímetros que definen las fronteras de un paisaje cultural en sus distintos gradientes, ya que con la articulación de puntos pertenecientes al paisaje cultural podemos organizarlo (Figura 4). En este caso tenemos tres gradientes que delimitan al paisaje cultural:

- Módulo territorial: Delimitación más amplia de un paisaje cultural. Su demarcación corresponde a la unión de los puntos que generan una gran poligonal donde se encuentran los criterios a resaltar en tanto a los distintos campos temáticos desarrollados en la caracterización.

- Componente paisajístico: Subdivisiones de los módulos territoriales, los cuales contienen distintas características vinculadas con expresiones culturales y naturales relevantes de mencionar.

- Unidad de paisaje cultural: Visión micro de un módulo territorial. Constituye la zona núcleo donde se expresan, se plasman los rasgos sobresalientes, representativos, esenciales que le dan identidad al paisaje cultural.

Toda esta delimitación deberá ser expresada en mapas, los cuales le darán pertinencia geofísica a la expresión. Sobre el mapa se dibuja en primera instancia el módulo territorial como una gran poligonal, a su interior los distintos componentes paisajísticos como secciones de ésta y posterior a ello, las unidades de paisaje cultural. Este ejercicio es una actividad que se tendrá que realizar de manera colectiva, al momento de que las expresiones culturales y naturales se encuentran en una localización definida, con contextos específicos con personas y en lugares concretos, el proceso de delimitación y jerarquización cobra vida.
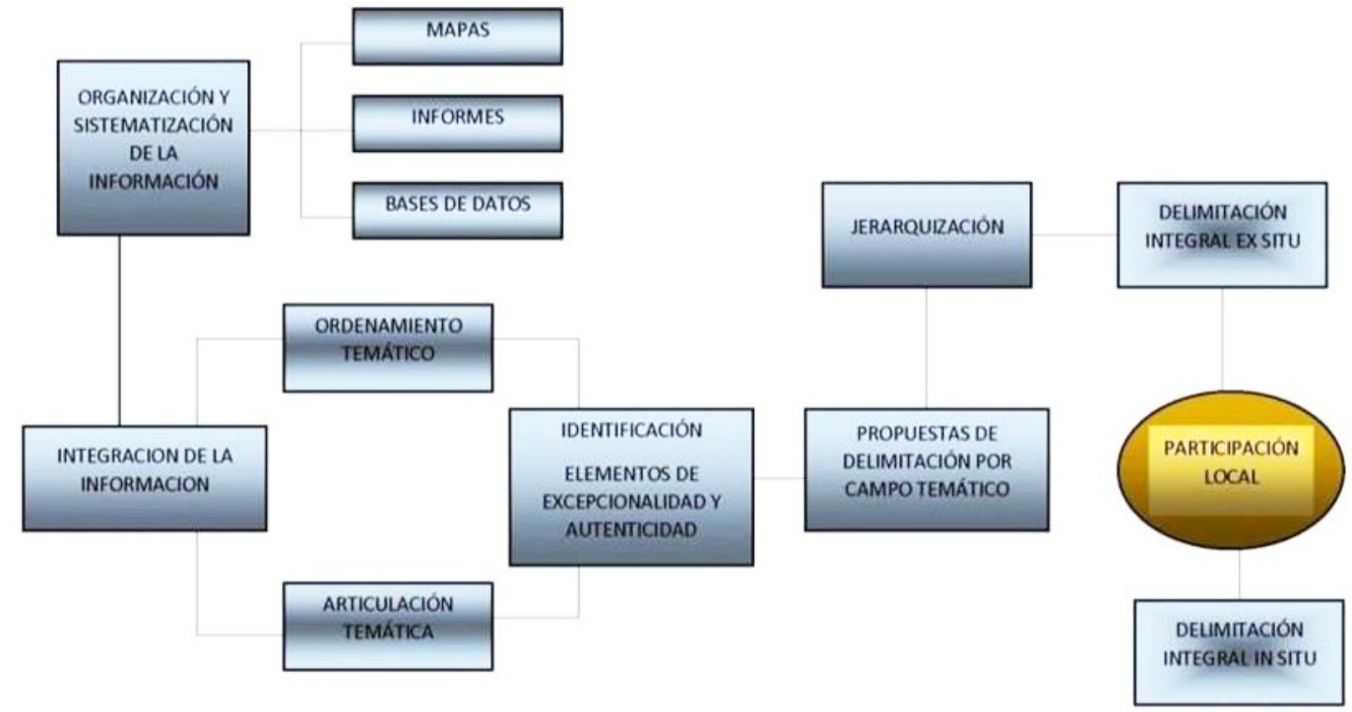

Figura 4. Integración, jerarquización y delimitación. 
Tanto los componentes paisajísticos como las unidades de paisaje cultural, usualmente son más de uno y, por lo tanto, requieren de una jerarquización según su importancia, la cual depende de criterios de valoración: integralidad, autenticidad y factor de riesgo. Cuando hablamos de la integralidad nos referimos a la mayor o menor cantidad de expresiones caracterizadas, ubicadas en una misma zona, región, comunidad o sitio geográfico. La integralidad la obtenemos mediante la conjunción de los distintos aspectos temáticos de la caracterización. Es importante señalar que los nombres de muchas unidades de Paisaje Cultural se dan por el criterio de integralidad. La autenticidad está relacionada o se destaca con la excepcionalidad de las expresiones, la importancia y la especificidad que tienen las mismas en cuanto a los módulos territoriales, los componentes paisajísticos y las unidades de Paisaje Cultural. Ésta tiene que comprenderse desde su mensaje, contexto y materialidad. El factor de riesgo tiene que ver con las amenazas internas y externas que las expresiones tienen. La determinación del factor de riesgo usualmente funciona para establecer planes de manejo. Cada uno de estos criterios poseen sus respectivas tablas de valoración para su llenado que nos arrojarán datos veraces y concretos para caracterizar y calificar jerarquías territoriales, al mismo tiempo nos generarán directrices para la planeación futura vinculada con la salvaguarda que atenúe las amenazas sobre el paisaje.

Con todos estos elementos: la integración, la delimitación, la jerarquización y la valoración de las expresiones que constituyen las distintas dimensiones del paisaje cultural, se encuentran en movimiento mediante la discusión de expertos, los cuales al llegar a un acuerdo, desarrollan y perfilan la información de acuerdo a la determinación de sus módulos, componentes y unidades de paisaje cultural teniendo con ello resuelta la primera parte del proceso, misma que tiene que continuar siendo socializada en los distintos lugares donde autoridades y población caracterizada se articule al estudio integrado. Parte de esta socialización estará la tarea de realizar una delimitación in situ con los actores locales, presentando la propuesta realizada por el equipo de trabajo, esto es importantísimo para su validación y complementación de información.

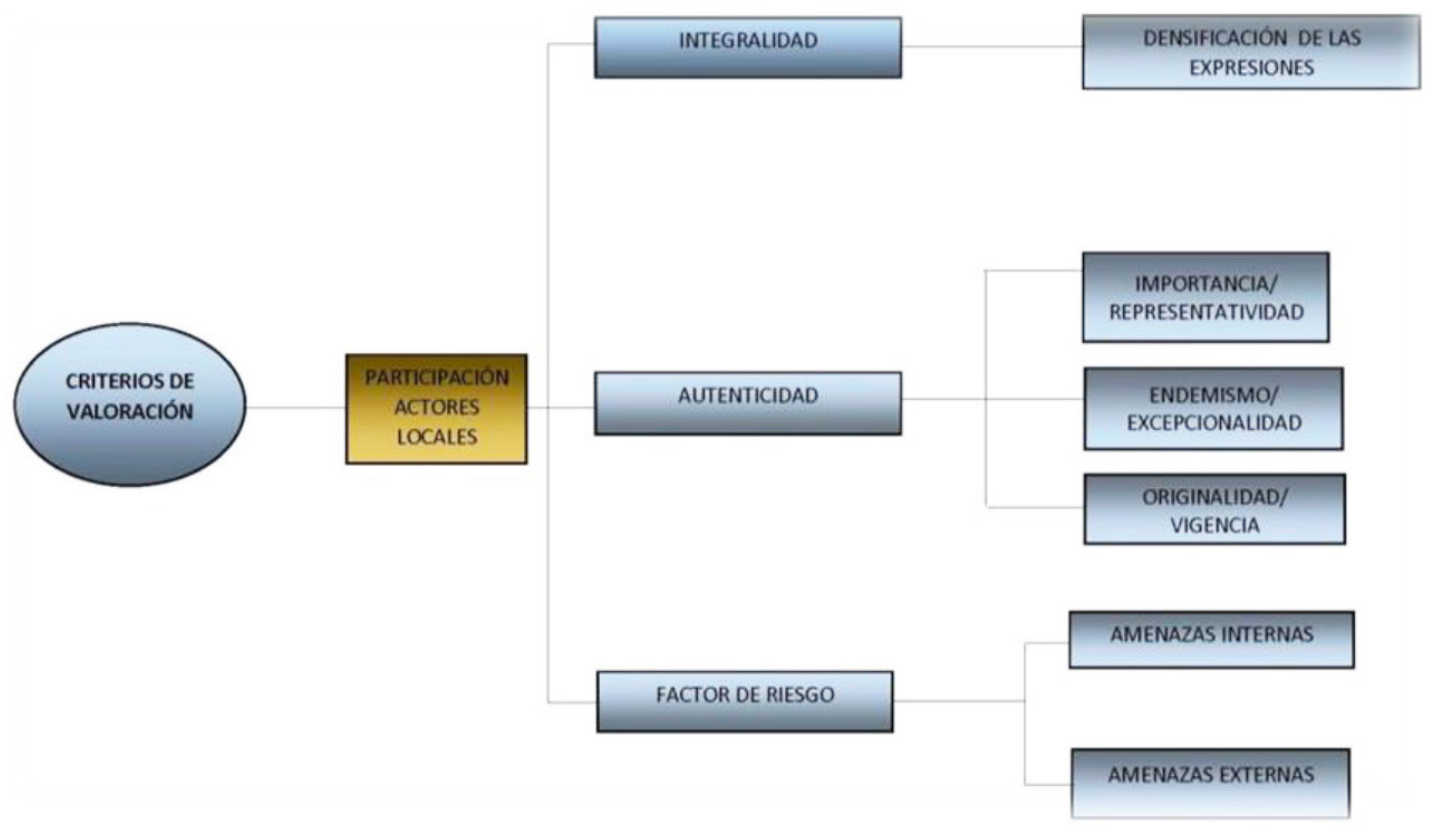

Figura 5. Valoración del Paisaje Cultural. 
La gestión de los paisajes culturales se enmarca dentro de tres ejes fundamentales: El fortalecimiento de las expresiones patrimoniales, el fomento del desarrollo humano y la gestión del territorio y el medio ambiente, parámetros fundamentales que nos guiarán a la formulación de planes, programas, proyectos los cuales deberán estar relacionados, insertados, articulados con los planes de ordenamiento territorial, planes estratégicos, de los gobiernos seccionales, locales y del gobierno central. Para la ejecución de los planes, programas, proyectos de gestión de paisajes culturales, se debe tener bien claro: Valores (valoración del paisaje cultural), principales amenazas (problemática del sitio), para plantear: objetivos, estrategias y acciones (Figura 5).

Partiendo de los diferentes elementos o aspectos que le otorguen valor a un paisaje cultural, se determinará cuáles son las diferentes amenazas que están poniendo en riesgo esos valores. Los objetivos enunciarán el fin o la meta que se pretende alcanzar para evitar la amenaza existente sobre un valor patrimonial de ese paisaje; para lo cual, se construirán estrategias que nos guiarán a conseguir los objetivos a través de la propuesta de una serie de pasos que las llamaremos acciones o actividades, reflejadas en proyectos puntuales a gestionarse.

A continuación, mencionamos tres grandes áreas de labor cultural: la investigación, la difusión y la conservación y salvaguardia; estas tres grandes áreas se vuelven estratégicas para el trabajo con colectivos locales en cuanto a la generación de grupos de trabajo destinados a incentivar el interés sobre el conocimiento y la conservación de lo suyo como forma de desarrollo local.

En cuanto a la investigación se pueden desencadenar distintos procesos relacionados con la generación de equipos de trabajo sobre temas puntuales que redunden en el planteamiento de proyectos $y / o$ planes de manejo específicos.

En cuanto a la difusión, es uno de los más atractivos cam- pos de acción y sobre todo con resultados inmediatos. En este sentido vale la pena realizar productos, eventos, donde exista una devolución de la información obtenida a las localidades involucradas, se difundan dichos resultados y puedan captar la atención de la población para la participación de actividades subsecuentes.

La conservación y la salvaguardia son actividades que pueden ser realizados desde distintos ámbitos; entendiéndose la conservación como una actividad cuyo principal objetivo es detener los procesos erosivos, de destrucción o extracción de determinadas expresiones, y la construcción de planes de salvaguardia que permiten formular las medidas necesarias para que las diferentes manifestaciones patrimoniales se sigan practicando y puedan continuar transmitiéndose a las generaciones futuras.

El manejo de los paisajes culturales debe convertirse en un instrumento de gestión social, política y económica, para así desarrollar intervenciones incluyentes, eficientes e interculturales sostenibles, que redunden en la conservación y fortalecimiento de los valores patrimoniales naturales y culturales, en el desarrollo local de una determinada sociedad (mejora de la calidad de vida) y propicie una adecuada gestión del territorio y su medio ambiente; convirtiéndose el patrimonio a través de un adecuado manejo del paisaje, en un motor dinamizador de la economía de los pueblos y del desarrollo de un determinado territorio.

\section{REFERENCIAS}

Convenio Mixto Ecuador- Colombia. (2015). Paisajes Culturales. Memorias Taller Gestión de Paisajes Culturales. Quito y Urcuquí. Ecuador.

León Bedoya, M. y Vázquez Estrada, A. (2015). Guía Metodológica para el Paisaje Cultural Ecuatoriano.

Instituto Nacional de Patrimonio Cultural del Ecuador. (2014). Paisaje Cultural cuenca baja del Guayas. Los ríos y el espacio fluvial en la conformación histórica del territorio. 